\title{
Possible role of glial cells in the onset and progression of Lyme
} neuroborreliosis

\author{
Geeta Ramesh ${ }^{1}$, Juan T Borda², Amy Gill², Erin P Ribka ${ }^{3}$, Lisa A Morici ${ }^{4}$, \\ Peter Mottram¹, Dale S Martin ${ }^{1}$, Mary B Jacobs ${ }^{1}$, Peter J Didier ${ }^{2}$ and \\ Mario T Philipp*1,4
}

Address: ${ }^{1}$ Division of Bacteriology and Parasitology, Tulane National Primate Research Center, Covington, LA, USA, ${ }^{2}$ Division of Comparative Pathology, Tulane National Primate Research Center, Covington, LA, USA, ${ }^{3}$ Division of Veterinary Medicine, Tulane National Primate Research Center, Covington, LA, USA and ${ }^{4}$ Department of Microbiology and Immunology, Tulane University Medical School, New Orleans, LA, USA

Email: Geeta Ramesh - gramesh@tulane.edu; Juan T Borda - jborda@tulane.edu; Amy Gill - afgill@tulane.edu; Erin P Ribka - peribka@mac.com; Lisa A Morici - Imorici@tulane.edu; Peter Mottram - pmottra@yahoo.com;

Dale S Martin -dmartin1@tulane.edu; Mary B Jacobs - mjacobs@tulane.edu; Peter J Didier - pjdidier@tulane.edu;

Mario T Philipp* - philipp@tulane.edu

* Corresponding author

Published: 25 August 2009

Journal of Neuroinflammation 2009, 6:23 doi:10.1186/1742-2094-6-23
Received: 24 July 2009

Accepted: 25 August 2009

This article is available from: http://www.jneuroinflammation.com/content/6/1/23

(c) 2009 Ramesh et al; licensee BioMed Central Ltd.

This is an Open Access article distributed under the terms of the Creative Commons Attribution License (http://creativecommons.org/licenses/by/2.0), which permits unrestricted use, distribution, and reproduction in any medium, provided the original work is properly cited.

\begin{abstract}
Background: Lyme neuroborreliosis (LNB) may present as meningitis, cranial neuropathy, acute radiculoneuropathy or, rarely, as encephalomyelitis. We hypothesized that glia, upon exposure to Borrelia burgdorferi, the Lyme disease agent, produce inflammatory mediators that promote the acute cellular infiltration of early LNB. This inflammatory context could potentiate glial and neuronal apoptosis.
\end{abstract}

Methods: We inoculated live B. burgdorferi into the cisterna magna of rhesus macaques and examined the inflammatory changes induced in the central nervous system (CNS), and dorsal root nerves and ganglia (DRG).

Results: ELISA of the cerebrospinal fluid (CSF) showed elevated IL-6, IL-8, CCL2, and CXCLI 3 as early as one week post-inoculation, accompanied by primarily lymphocytic and monocytic pleocytosis. In contrast, onset of the acquired immune response, evidenced by anti-B. burgdorferi C6 serum antibodies, was first detectable after 3 weeks post-inoculation. CSF cell pellets and CNS tissues were culture-positive for B. burgdorferi. Histopathology revealed signs of acute LNB: severe multifocal leptomeningitis, radiculitis, and DRG inflammatory lesions. Immunofluorescence staining and confocal microscopy detected B. burgdorferi antigen in the CNS and DRG. IL-6 was observed in astrocytes and neurons in the spinal cord, and in neurons in the DRG of infected animals. CCL2 and CXCLI3 were found in microglia as well as in endothelial cells, macrophages and T cells. Importantly, the DRG of infected animals showed significant satellite cell and neuronal apoptosis.

Conclusion: Our results support the notion that innate responses of glia to $B$. burgdorferi initiate/ mediate the inflammation seen in acute LNB, and show that neuronal apoptosis occurs in this context. 


\section{Background}

Lyme neuroborreliosis (LNB) is caused by the spirochete Borrelia burgdorferi. It manifests in $10-15 \%$ of untreated Lyme disease patients [1]. LNB affects both the peripheral and the central nervous systems (CNS), resulting in acute and chronic inflammation accompanied with neurological deficits that may persist for the lifetime of a patient [2]. Neuroborreliosis may present as meningitis, cranial neuropathy, transverse myelitis, acute radiculoneuropathy or, rarely, as encephalomyelitis [3]. Early symptoms after an acute attack of LNB may include severe headaches, chronic fatigue and flu-like symptoms, facial-nerve paralysis, and motor dysfunction presenting as acute ataxia with pain in the back and extremities of limbs, accompanied by cognitive disorders and depression [4].

A sign of acute meningitis of both bacterial and viral origin is migration of large numbers of leukocytes into the subarachnoid space, with such pleocytosis reaching values of 100 to 1000 cells per $\mu \mathrm{L}$ [5]. Under normal conditions, cerebrospinal fluid (CSF) contains 1-5 leukocytes per $\mu \mathrm{L}$ [6]. In meningitis caused by bacteria such as Neisseria meningitidis, Haemophilus influenza, or Streptococcus pneumoniae the local production of cytokines and chemokines by glial and endothelial cells upon contact with pathogens is currently regarded as the initial step in regulating the directed migration of distinct leukocyte populations to an inflammatory site within the CNS [7-10]. In Lyme meningitis the cellular sources of these mediators are unknown.

The CSF of LNB patients shows abnormalities within 3 to 6 weeks after infection, manifested as mononuclear pleocytosis, persistent plasma cells, intrathecal synthesis of $B$. burgdorferi-specific immunoglobulins and presence of $B$. burgdorferi DNA [11]. Immune mediators such as cytokines and chemokines implicated in playing a role in the pathogenesis of various inflammatory diseases of the nervous system have also been found in the CSF of LNB patients [12-19]. Further, microscopic evaluation of lesions from patients with LNB shows perivascular monocytic and lymphocytic cell infiltration concomitant with the presence of $B$. burgdorferi DNA $[20,21]$.

Recently, we reported that the interaction of B. burgdorferi with rhesus monkey brain parenchyma elicits the inflammatory mediators IL-6, IL-8, IL-1beta and CXCL13 from glial cells, with concomitant oligodendrocyte and neuronal apoptosis [22]. In addition, primary cultures of microglia or astrocytes produced IL-6, TNF-alpha, IL-8, and the macrophage inflammatory proteins CCL3 and CCL4 in the presence of live B. burgdorferi [23]. Several of these mediators are associated with LNB [24,25], play a major role in the recruitment of leukocytes into the subarachnoid space in various types of infectious meningitis [26], and in the inflammatory response mounted by the CNS in other neurodegenerative diseases such as multiple sclero- sis and experimental autoimmune encephalomyelitis $[27,28]$. We therefore reasoned that glial cells could be an early source of the cytokines and chemokines detected in the CSF during LNB. We further anticipated that this inflammatory context could potentiate glial and neuronal apoptosis, based on our earlier observations that documented that live B. burgdorferi induced inflammation and oligodendrocyte and neuronal apoptosis in brain explants ex vivo, and following intracerebral inoculation in vivo [22].

To address our hypotheses we devised an in vivo model of acute LNB in the rhesus monkey. Five rhesus macaques were given intrathecal inoculations with live B. burgdorferi, and 2 additional animals were given sham inoculations and served as controls. CSF and serum samples were serially collected over a 6-week period from 2 of the infected animals and one control, and over a 12-week period from the other 3 animals and the other control. Relative concentrations of cytokines and chemokines were determined in CSF and serum by multiplex and sandwich ELISA assays, to determine the immune mediators that were specifically associated with the initiation of Lyme meningitis along with the appearance of pleocytosis. CSF cell pellets, and tissues from various regions of the brain and spinal cord were cultured for spirochetes to evaluate the presence of active infection. Levels of anti-C6 antibodies [29] were determined in serial serum samples to monitor the appearance of the acquired immune response against $B$. burgdorferi. Histopathological evaluation, immunohistochemistry, immunofluorescence staining and confocal microscopy of sections from the brain, spinal cord, dorsal root ganglia (DRG) and heart tissues were performed post-necropsy to detect the presence of inflammatory lesions, $B$. burgdorferi antigen, and to identify the cells that produced immune mediators. We also looked for glial and neuronal apoptosis in the parenchyma of the brain and spinal cord, and in DRG by the in situ TUNEL assay. The results of these evaluations are described herein.

\section{Methods \\ Spirochetal inoculum}

B. burgdorferi strain B31 clone 5A19 spirochetes, passage one, isolated from an ear biopsy of a previously infected mouse, were grown in Barbour-Stoenner-Kelly (BSK)-H medium supplemented with $6 \%$ rabbit serum and antibiotics (Rifampicin at $45.4 \mathrm{mg} / \mathrm{ml}$, Phosphomycin at 193 $\mathrm{mg} / \mathrm{ml}$ and Amphotericin at $0.25 \mathrm{mg} / \mathrm{ml}$ ) (Sigma, St. Louis, MO) to late logarithmic phase under microaerophilic conditions. Spirochetes were pelleted at $2000 \times \mathrm{g}$ for $30 \mathrm{~min}$ at RT. At the end of the run the rotor was left to coast without breaking so as to minimize damage to the live spirochetes. The culture was washed twice using phosphate buffered saline (PBS) pH 7.2 (Invitrogen, Grand Island, NY) and resuspended in RPMI 1640 medium (Bio- 
whittaker, Walkersville, MD) to contain a suspension of 1 $\times 10^{8}$ spirochetes $/ \mathrm{ml}$.

\section{Animals and intrathecal inoculation}

Seven 3-7-year old male rhesus macaques (Macaca mulatta) of Chinese origin were used in this study. The inoculation protocol was approved by the Institutional Animal Care and Use Committee of the Tulane National Primate Research Center. Anesthetized animals received up to $1 \mathrm{ml}$ of RPMI 1640 medium with $1 \times 10^{8}$ spirochetes $(\mathrm{n}=5)$, or no spirochetes $(\mathrm{n}=2)$ into the cisterna magna, after removal of an equivalent volume of CSF. This dose was found to be safe in studies involving intrathecal inoculation of Treponema pallidum, another spirochete, in rhesus macaques [30]. Similar inoculum doses were used previously in the rhesus monkey [31-34]. To monitor CNS inflammation following inoculation, CSF (0.5-1.0 ml) and serum ( $5 \mathrm{ml}$ of blood) were collected on a weekly basis for 4 weeks, and then once every two weeks until the end of the study for each animal. Two inoculated animals (DR50, EL81) and one control (EL66) were necropsied at six weeks post-inoculation (PI) and three inoculated animals (DH50, EP51, CH82) and one control (EJ86) at 12 weeks PI. The procedure used for euthanasia was consistent with the recommendations of the American Veterinary Medical Association's Panel on Euthanasia.

\section{CSF cell enumeration, and B. burgdorferi culture}

CSF samples were maintained on ice after collection until processed. Total cell numbers were determined using a Reichert Bright-Line metalized hemocytometer (Thermo Fisher Scientific, Waltham, MA) within 30 min of collection. For cytospin, preparations were made by centrifuging the CSF at $300 \times \mathrm{g}$ at $4{ }^{\circ} \mathrm{C}$ for $10 \mathrm{~min}$. The cell pellet was resuspended in $100 \mathrm{ml}$ of fetal bovine serum, loaded in a Shandon EZ cytofunnel set up on positively charged slides, and spun at $700 \mathrm{rpm}$ for $7 \mathrm{~min}$ with minimum acceleration on a Shandon Cytospin centrifuge (Thermo Fisher Scientific). Slides were air-dried and stained with Wright stain (Fisher Scientific, Pittsburg, PA), mounted, and stored at RT until evaluation. Slides were examined for cellular composition and cell morphology. A 100-200 nucleated-cell differential count was performed from multiple random areas of each slide under a $40 \times$ objective. The CSF supernatant after removal of cells was collected and spun down at $8000 \times \mathrm{g}$ at $4^{\circ} \mathrm{C}$ for $20 \mathrm{~min}$. The supernatant was aliquoted and frozen at $-70^{\circ} \mathrm{C}$ for evaluation of immune mediators. The pellet was resuspended in $10 \mathrm{ml}$ BSK-H medium, supplemented with $6 \%$ rabbit serum and antibiotics as described above (Sigma) for culture of B. burgdorferi.

\section{Detection of anti-VIsE (C6) antibodies in serum}

Serum antibody levels to the VlsE C6 peptide (B. burgdorferi B31) were quantified by ELISA using a procedure described previously [29]. As is customary, the cut-off line for positive ELISA values was set at the mean value of all of the pre-immune serum specimens plus three times the standard deviation of that mean. The probability that an ELISA value above this cut-off line is negative is $\mathrm{p}=0.003$.

\section{Quantification of immune mediators in CSF and serum}

CSF and serum cytokines and chemokines were quantified with the Bio-Plex Human Cytokine 17-Plex Panel following the manufacturer's instructions (Bio-Rad, Hercules, CA). The analytes detected by this panel are: $\mathrm{Hu}$ IL-1beta, Hu IL-2, Hu IL-4, Hu IL-5, Hu IL-6, Hu IL-7, Hu IL-8, Hu IL-10, Hu IL-12, Hu IL-13, Hu IL-17, Hu G-CSF, Hu GMCSF, Hu IFN-gamma, Hu MCP-1/CCL2, Hu MIP1beta/CCL4, Hu TNF-alpha. The multiplex plate was read using a Bio-Plex 200 Suspension Array Luminex System (Bio-Rad). CXCL13 concentration was measured with a sandwich ELISA (R\&D, Minneapolis, MN). As with the serology ELISA, the cut-off line for positive Bio-Plex and sandwich ELISA values was set at the mean value for each mediator of all of the pre-infection and control CSF specimens plus three times the standard deviation of that mean.

\section{Collection of tissues for histopathological evaluation, detection of intracytoplasmic localization of immune mediators, and detection of B. burgdorferi by culture}

Tissues were collected from various regions of the brain and spinal cord and DRG, and fixed in formalin or Z-fixative (Anatech, Battle Creek, MI) for routine histopathological evaluation. For the purpose of detecting intracytoplasmic localization of cytokines, fresh unfixed tissues were collected from various regions of the brain and spinal cord, as well as DRG at necropsy, and immediately processed for blocking of intracytoplasmic cytokines (modification of the method previously described [35], by incubation of tissue slices for four hours in RPMI medium (Invitrogen) containing 10\% fetal bovine serum (Invitrogen) and the fungal metabolite brefeldin A (Invitrogen), which blocks export of intracellular proteins via the endoplasmic reticulum. Tissues were then fixed in $2 \%$ paraformaldehyde in PBS pH 7.0 (USB, Cleveland OH), and cryopreserved as described previously [35]. Tissue samples from various regions of the brain and spinal cord were also collected at necropsy in BSK-H medium, supplemented with $6 \%$ rabbit serum and antibiotics (Sigma) for detection of $B$. burgdorferi by culture.

Immunofluorescence staining of intracytoplasmic immune mediators, phenotypic markers of producer cells and of cells in inflammatory lesions

For in situ analysis, the cryopreserved tissues were cryosectioned into $16-\mu \mathrm{m}$ sections as previously described [35]. Tissues collected in formalin or fixed with Z-fixative were also sectioned into $10-15 \mu \mathrm{m}$ sections, depending on the 
availability of tissue. Presence of inflammatory lesions was determined by routine histopathological evaluation of tissues sectioned at $5 \mu \mathrm{m}$ and stained with hematoxylin and eosin $(\mathrm{H} \& \mathrm{E})$. Immunohistochemical staining was done using several monoclonal and polyclonal antibodies (anti-CD3, CD20, and CD68, Table 1). All histological sections were incubated with the primary antibody for 1 hour at room temperature, followed by biotinylated antirabbit or anti-mouse secondary antibodies (Dako) as appropriate for 30 minutes. Finally, sections were incubated with avidin-biotin complex (ABC) (Vector labs, Burlingame, CA) for 30 minutes, and the reaction was visualized with 3,3'-diaminobenzidine (Dako) as the chromogen. Sections were subjected to immunofluorescence staining as previously described [22]. The primary antibodies against various immune mediators, cell phenotypic markers and B. burgdorferi are listed in Table 1. Relevant isotype controls (Sigma) at the concentration of the corresponding primary antibodies were also included.

\section{Qualitative and quantitative assessment of glial and neuronal apoptosis}

Glial and neuronal apoptosis was assessed by the in situTUNEL assay in tissues collected from the brain and spinal cord as well the DRG, that were directly fixed in $2 \%$ paraformaldehyde at collection and cryopreserved and frozen as previously described [22]. Sections were stained for any one of the following brain cell markers: NeuN (neurons), IBA-1 (microglia), GFAP-cy3 (astrocytes), or S-100 (astrocytes, oligodendrocytes, Schwann cells, satellite cells) by incubation with the appropriate primary antibody (Table 1) followed by secondary antibodies conjugated with Alexa Flour 568. Sections were fixed in 2\% paraformaldehyde for $15 \mathrm{~min}$, followed by a 15-min wash in PBS. Sections were then subjected to the terminal deoxynucleotidyl transferase mediated UTP nick end labeling (TUNEL)-ApopTagPlus fluorescein in situ apoptosis assay (Chemicon, Temecula CA) as per the manufacturer's instructions. Sections were also stained with anti-B. burgdorferi antibody as described above followed by secondary antibody conjugated to Alexa Fluor 633. Contiguous sections stained with isotype controls at the respective concentrations of the primary antibody were included. To confirm the identity of S-100-staining cells, S-100-stained (Alexa Fluor 568) sections were also stained with antiGFAP followed by secondary antibody conjugated to Alexa Fluor 633 (blue), before doing the TUNEL assay. Cells that were only positive for S-100 (labeled red) were regarded as oligodendrocytes in the CNS and Schwann cells and/or satellite cells in the DRG [36], while those that were labeled pink due to an overlap of S-100 (red) and GFAP (blue) were considered to be astrocytes. Slides were washed and mounted as described above and stored at $4{ }^{\circ} \mathrm{C}$ in the dark until viewed. The percentage of apoptotic cells from ten fields were counted from each section (more than 500 cells in all cases). The total number of NeuN or S-100 positive cells respectively in each section was ascertained, followed by the percentage of cells that colocalized with the TUNEL signal for each cell marker, All counts were made by viewing slides under a fixed magnification of $63 \times\left(\right.$ corresponding to an area of $0.05 \mathrm{~mm}^{2}$ ) using the confocal microscope (see below).

\section{Confocal microscopy}

Confocal microscopy was performed using a Leica TCS SP2 confocal microscope (Leica Microsystems, Exton, PA) as previously described [22]. Photoshop CS3 (Adobe systems Inc., San Jose, CA) was used for image processing.

\section{Statistical analysis}

The statistical significance of the apoptosis data was evaluated using the one-way ANOVA non-parametric analysis, followed by the Tukey's stringency test using PRISM software (IBM).

\section{Results \\ Intrathecal inoculation with B. burgdorferi results in active, persistent CNS infection}

Live $B$. burgdorferi spirochetes were recovered from the CSF cell pellets of all but one of the inoculated animals at various time points PI, as follows: animals DR50 and EL81 at week 6, DH50 at week 2 and EP51 at week 10, except for animal CH82, whose CSF cell-pellet cultures yielded no spirochetes. Tissues harvested at necropsy from the dura mater and the cervical spinal cord of one of the two animals (EL81) that were inoculated with B. burgdorferi and euthanized 6 weeks PI were also culture positive for B. burgdorferi. CSF cell-pellet or tissue cultures of the control animals were negative throughout.

\section{Early appearance of pleocytosis and inflammatory mediators in CSF}

CSF pleocytosis was evident in all of the B. burgdorferiinoculated animals as early as one week PI; specimens from the control animals were essentially free of cells (Table 2). Pleocytosis was minimal in $\mathrm{CH} 82$, which peaked to about 35 leukocytes/ $\mu$ l by week two PI. The evaluation of the percentage of various leukocytes (differential counts) of cytospins prepared from the CSF samples showed a predominance of lymphocytes and macrophage/monocytes. The differential counts of leukocytes in the CSF of all of the animals with a pleocytosis $>50$ cells/ $\mu \mathrm{l}$ is shown in Fig. 1 .

CSF from infected animals showed levels above the cut-off value for the cytokine IL-6 in animals DR50, EL81 and DH50, between week 1-3 (Fig 2a). Animal EP51 showed levels of IL- 6 just exceeding the cut-off value at weeks 1 and 2 PI. The chemokine IL- 8 was significantly elevated in the CSF of all of the inoculated animals (Fig 2b), reaching 
Table I: Primary antibody and antibody/fluorochrome-conjugates against various immune mediators, B. burgdorferi, and cell phenotypes

\begin{tabular}{|c|c|c|c|}
\hline MEDIATOR/CELL TYPE & PRIMARY AB/SOURCE & ISOTYPE & DILUTION/CONCENTR. \\
\hline IL-6 & $\begin{array}{c}\text { anti-human IL-6 } \\
\text { (Abcam Inc. Cambridge, MA) }\end{array}$ & Rabbit lgG & $1: 1000$ \\
\hline IL-8 & $\begin{array}{l}\text { anti-human IL-8 } \\
\text { RDI Flanders, NJ }\end{array}$ & Rabbit lgG & $10 \mu \mathrm{g} / \mathrm{ml}$ \\
\hline \multirow[t]{2}{*}{$\mathrm{CCL} 2$} & $\begin{array}{l}\text { anti-human } \mathrm{CCL} 2 \\
\text { (BD) }\end{array}$ & Mouse $\lg G_{1}$ & $10 \mu \mathrm{g} / \mathrm{ml}$ \\
\hline & $\begin{array}{l}\text { anti-human CCL2 } \\
\text { (Abcam) }\end{array}$ & Rabbit lgG & $\mathrm{I}: 10$ \\
\hline CXCLI3 & $\begin{array}{l}\text { anti-human } \mathrm{CXCLI3} \\
(\mathrm{R} \& \mathrm{D})\end{array}$ & goat $\lg G$ & $5 \mu \mathrm{g} / \mathrm{ml}$ \\
\hline \multirow[t]{2}{*}{ B. burgdorferi } & $\begin{array}{l}\text { anti-whole cell preparation } \\
\text { (Accurate Chemicals, Westbury, NY) }\end{array}$ & Rabbit IgG & $\mathrm{I}: 250$ \\
\hline & $\begin{array}{c}\text { anti- B. burgdorferi-FITC } \\
\text { (Kirkegaard and Perry, Gaithersburg, MD) }\end{array}$ & Goat & $1: 10$ \\
\hline \multirow[t]{2}{*}{ Astrocyte } & $\begin{array}{l}\text { anti-human GFAP-cy3 } \\
\text { (Sigma St Louis, MO) }\end{array}$ & Mouse $\lg G_{1}$ & $\mathrm{I}: 200$ \\
\hline & $\begin{array}{l}\text { anti-human GFAP } \\
\text { (Sigma) }\end{array}$ & Mouse $\lg G_{1}$ & $\mathrm{I}: 200$ \\
\hline Astrocyte, Oligodendrocyte, Schwann cell, satellite cell & $\begin{array}{l}\text { anti-bovine S-100 } \\
\text { (Sigma) }\end{array}$ & Rabbit lgG & $1: 1000$ \\
\hline Microglia & $\begin{array}{c}\text { anti-lbal synthetic peptide } \\
\text { (Wako Pure Chemicals, Richmond, VA) }\end{array}$ & Rabbit lgG & $1: 100$ \\
\hline Endothelial cells & $\begin{array}{l}\text { anti-human GLUT-I } \\
\text { (Chemicon) }\end{array}$ & Rabbit lgG & $\mathrm{I}: 50$ \\
\hline Neuron & $\begin{array}{l}\text { anti-mouse NeuN } \\
\text { (Chemicon) }\end{array}$ & Mouse $\lg G_{1}$ & $\mathrm{I}: 20$ \\
\hline $\mathrm{T}$ cell & $\begin{array}{c}\text { anti-human CD3 } \\
\text { (Dako, Carpinteria, CA) }\end{array}$ & Mouse $\lg G 2 a$ & $\mathrm{I}: 10$ \\
\hline B cell & $\begin{array}{l}\text { anti-human CD20 } \\
\text { (Dako) }\end{array}$ & Mouse IgGI & $\mathrm{I}: 200$ \\
\hline Macrophage & $\begin{array}{l}\text { anti-human CD68 } \\
\text { (Dako) }\end{array}$ & Mouse IgGI & $1: 50$ \\
\hline
\end{tabular}

maximum levels ranging from 10.9 to $35 \mathrm{pg} / \mathrm{ml}$ between weeks 1 and 2 PI. Monocyte chemoattractant protein$1 \mathrm{MCP}-1 / \mathrm{CCL} 2$ was significantly elevated in all of the infected animals (Fig 2c) except CH82, ranging between $350 \mathrm{pg} / \mathrm{ml}$ to $500 \mathrm{pg} / \mathrm{ml}$ by week 2 PI. The levels of IL-6 in the CSF were higher than those observed in the serum of all of the infected animals, except CH82, (Table 3), indicating that this cytokine was produced primarily intrathecally. On the other hand, IL-8 levels were much higher in serum than they were in CSF (Table 3). The levels of CCL2 were considerably higher in the CSF compared to those found at the corresponding time points in serum, suggest- 
Table 2: Cerebrospinal fluid pleocytosis

\begin{tabular}{|c|c|c|c|c|c|c|c|c|c|}
\hline \multirow[t]{2}{*}{ ANIMAL } & \multicolumn{9}{|c|}{ CEREBROSPINAL FLUID NUCLEATED CELL COUNT/ $\mu$ I } \\
\hline & wk-0 & wk- I & wk-2 & wk-3 & wk-4 & wk-6 & wk-8 & wk-10 & wk-12 \\
\hline DR50 & 1 & 371 & 119 & 540 & 66 & 72 & & & \\
\hline EL8I & 0 & 133 & 62 & 22 & 19 & 9 & & & \\
\hline EL66 & 3 & 0 & 2 & 5 & 0 & 8 & & & \\
\hline EP5 I & 0 & 32 & 84 & 25 & 15 & 12 & 5 & 0 & 3 \\
\hline CH82 & 0 & 8 & 35 & 11 & 7 & 2 & I & 0 & 0 \\
\hline DH50 & 5 & 213 & 114 & 0 & 92 & 161 & 40 & 10 & 1 \\
\hline EJ86 & 0 & 0 & 3 & 0 & I & 6 & 18 & 0 & 3 \\
\hline
\end{tabular}

Total number of leukocytes/ $\mu \mathrm{I}$ of CSF as a function of time PI, in animals DR50 and EL8I (up to 6 weeks PI) and EP5I, CH82 and DH50 (up to I2 weeks PI) and respective controls (EL66, EJ86).

ing, once again, a predominantly CNS origin for this chemokine. The concentration of the B-lymphocyte chemokine CXCL13/BLC was elevated above the cut-off value in animals DR50, DH50, EL81, and EP51, reaching peak values of around $5500 \mathrm{pg} / \mathrm{ml}$ between weeks 2 and 4 PI (Fig 2d). The CSF levels of CXCL13 were higher in three out of four of the inoculated animals (DR50, EL81, and DH50) as compared to those in paired serum specimens (Table 3), implying a possible CNS origin for this mediator as well. The very early appearance of inflammatory mediators (week 1-2 PI) in the CSF indicates that innate immune responses are at play. In addition, the very high serum concentrations of IL- 8 detected as early as week 1 PI, much higher than the corresponding CSF levels, are data to suggest that the infection became systemic soon after the intrathecal inoculation.

\section{Evaluation of the time of onset of the acquired immune response}

The evaluation of the time of onset of acquired immunity in the periphery was done by serially quantifying anti-VlsE serum antibodies. VlsE, the antigenic variation lipoprotein of B. burgdorferi, is expressed by the spirochete uninterruptedly upon the initiation of infection in mammals. We measured the anti-VlsE antibody response by quantifying antibodies to the VlsE C6 peptide. The earliest that this response was detected was by week 3 PI (animal DR50), Fig. 3A. In all of the other animals that had received a $B$. burgdorferi inoculation the anti-C6 response appeared between weeks 4 and 6 PI, except for animal CH82 (Fig. 3E), who did not have a detectable anti-C6 response. No anti-C6 response was detected in control animals (Fig. 3F, 3G).
Histopathological evidence of Lyme meningitis, radiculitis, and inflammation in the DRG, along with evidence of $B$. burgdorferi antigen in both the CNS and peripheral nervous system (PNS) of infected animals

Histopathological evaluation of tissues collected from the 2 animals that were euthanized at 6 weeks PI revealed severe multifocal lymphocytic, monocytic and plasmacytic leptomeningitis in the brain and spinal cord. Radiculitis was evidenced by inflammatory infiltrates in the nerve roots of the cervical, thoracic, lumbar and sacral spinal cord. Similar lesions were seen in animal DH50, which was euthanized at 12 weeks PI. A representative image of brain leptomeningitis is shown in Fig 4A. The cellular infiltrates contained, in decreasing order of abundance, B lymphocytes (CD20+), T lymphocytes (CD3+), and monocyte/macrophages $\left(\mathrm{CD}^{+} 8^{+}\right)$. Figure $4 \mathrm{~B}$ depicts a confocal micrograph of a lesion found in the dura mater of animal DR50 showing the presence of T cells, B cells and monocyte/macrophages. Inflammatory infiltrates in the vicinity of $B$. burgdorferi antigen were observed in the dura mater (not shown) and frontal cortex of animals DR50 (Fig. 4C), EL81 and DH50. As with the meninges, the parenchymal cell infiltrates were composed chiefly by $\mathrm{B}$ and $\mathrm{T}$ lymphocytes and few macrophages. B. burgdorferi antigen was also present in tissues collected from the periventricular areas and spinal cord of infected animals (not shown). Radiculitis seen as inflammation of the dorsal roots collected from the cervical, thoracic, lumbar, and sacral spinal cord was observed in animals DR50, EL81 (6week-long infection) and DH50 (12-week). A representative image of radiculitis is depicted in Fig. 4D. Inflammation and presence of $B$. burgdorferi antigen was also observed in the DRG, in animals DR50 and DH50. A 
A

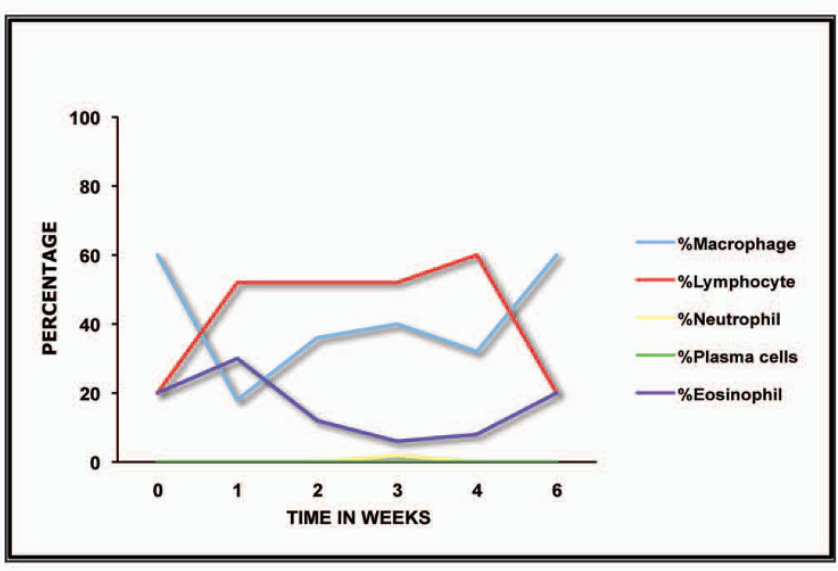

C

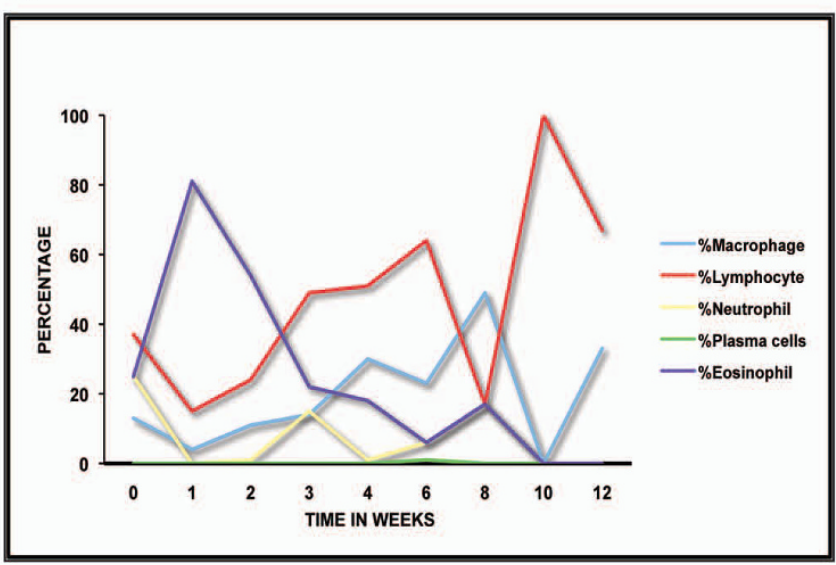

B

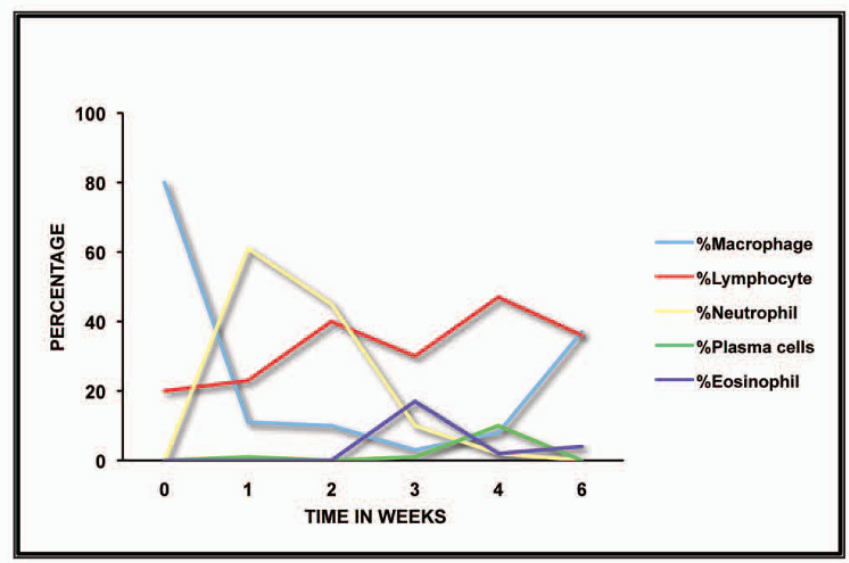

D

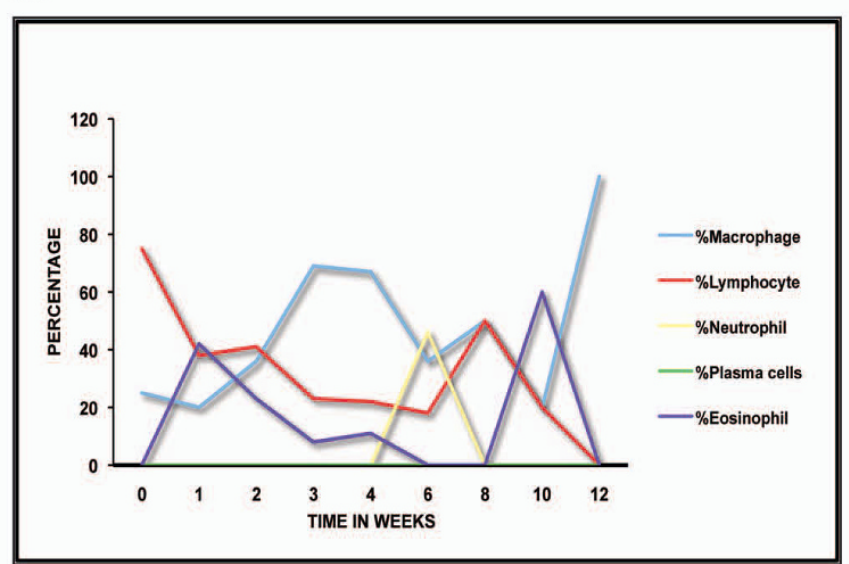

Figure I

CSF pleocytosis is primarily lymphocytic and monocytic. Leukocyte differential count in CSF cytospin-smears showing the percentage of neutrophils, macrophages, lymphocytes, plasma cells and eosinophils found over time in animals with a pleocytosis higher than 50 cells/ $\mu$ L (A. EL8I, B. DR50, C. DH50, D. EP5I).

chronic type of inflammation of DRG from animal DH50 is shown in Fig 4E. The presence of B. burgdorferi antigen in the vicinity of CD3-labeling-T cells in the DRG is shown in Fig. 4F. No inflammatory lesions were detected at necropsy in the remaining animals that were given a $B$. burgdorferi inoculation and were euthanized at 12-weeks PI (EP51 and CH82), or in the control animals.

\section{Glial cells and neurons are among the producers of inflammatory mediators}

IL-6 was produced by both astrocytes and neurons, as visualized by intracytoplasmic staining of spinal cord tissues from three of the five $B$. burgdorferi-inoculated animals (DR50, EL81 and DH50). Fig. 5A shows IL-6 produced by astrocytes in the spinal cord. IL- 6 was also found in neurons as well as extracellular in the DRG of animals DR50 and DH50 (Fig. 5B). CXCL13 and CCL2, two of the medi- ators produced chiefly in the intrathecal compartment, were localized to microglia in the spinal cord (Fig. 5C and Fig. 5D respectively). CXCL13 was also detected in CD68labeled macrophages in the lesions (not shown). In addition, CCL2 and CXCL13 were present in endothelial cells, especially in the periventricular areas of the brain (not shown). IL-8 was not detectable in any of the tissues at the time of necropsy.

IL-6, CCL2 and CXCL13 were undetectable in comparable tissues from control animals (Fig. 5E, F, and 5G). No IL-6 was detected in astrocytes from the spinal cord or in neurons from the DRG of a control animal (Fig 5E and 5F, respectively). Similarly, microglia from the spinal cord of control animals were devoid of mediators (IL-6, IL-8, CCL2 or CXCL13). A representative image of microglia lacking CCL2 is shown in Fig 5G. Non-specific signals 
Table 3: Peak CSF and corresponding serum values $(\mathrm{pg} / \mathrm{ml})$ of immune mediators in animals that were inoculated with $B$. burgdorferi.

\begin{tabular}{|c|c|c|c|c|c|}
\hline MEDIATOR & DR50 & EL8 I & EP5I & DH50 & $\mathrm{CH} 82$ \\
\hline IL-6 & $(w k-1)$ & $(w k-1)$ & $(w k-1)$ & $(w k-1)$ & $(w k-I)$ \\
\hline CSF & $17.8 \pm 0.4$ & $10 \pm 0.9$ & $3.7 \pm 0.5$ & $46.9 \pm 0.2$ & $2.9 \pm 0.7$ \\
\hline SERUM & $0.7 \pm 0.2$ & $0.3 \pm 0.05$ & $1 \pm 0.2$ & 0 & $3.9 \pm 0.5$ \\
\hline IL-8 & $(w k-1)$ & (wk-2) & (wk-2) & $(w k-1)$ & (wk-2) \\
\hline CSF & $33.4 \pm 4.2$ & $15.7 \pm 0.1$ & $21.9 \pm 1.0$ & $34.5 \pm 0.9$ & $10.9 \pm 2.0$ \\
\hline SERUM & $832.8 \pm 75$ & $697.6 \pm 86.2$ & $625.6 \pm 3.7$ & $3442 \pm 149.2$ & $422.4 \pm 25$ \\
\hline CCL2/MCP-I & $(w k-2)$ & (wk 2) & $(w k-3)$ & $(w k-3)$ & \\
\hline CSF & $475.9 \pm 25.2$ & $345.6 \pm 62.3$ & $404.5 \pm 6.8$ & $442.3 \pm 6.8$ & $*$ \\
\hline SERUM & $\mid 14.1 \pm 6.5$ & $71.8 \pm 0.4$ & $106.2 \pm 2.8$ & $39 \pm 11.2$ & \\
\hline CXCLI3/BLC & $(w k-3)$ & (wk-2) & (wk-4) & $(w k-3)$ & \\
\hline CSF & 5500 & 811.5 & 779 & $5317.8 \pm 70.5$ & $*$ \\
\hline SERUM & 300 & 748 & $122 \mid$ & 199 & \\
\hline
\end{tabular}

The time points at which peak values of various immune mediators (pg/ml) were observed in the CSF and corresponding values found in the serum of $B$. burgdorferi-infected animals are shown. Data represent the mean \pm SD of duplicate determinations, except for CXCLI 3 in animals DR50, EL8I, and EP5I, where remaining CSF volume available only permitted a single determination.

* CSF concentrations of CCL2 and CXCLI3 for animal CH82 were not significantly elevated with respect to control animals.

were absent in contiguous sections that were stained with immunoglobulin isotype controls at the concentrations of the respective primary antibodies, followed by the corresponding secondary antibodies.

\section{Glial and neuronal apoptosis}

All of the infected animals except CH82 showed significant levels of both Schwann/satellite cell and neuronal apoptosis in the DRG as compared to that seen in the respective controls. The percentage of DRG Schwann/satellite cells (S-100+/GFAP- staining cells) and neurons undergoing apoptosis in each of the animals in the study, as assessed by the in situ TUNEL assay is shown in Fig. 6A. Schwann/satellite cells showed significant levels of apoptosis ranging from $4.35 \pm 2.39 \%(\mathrm{p}<0.0001)$ to $10.35 \pm$ $3.11 \%(\mathrm{p}<0.0001)$. Neuronal apoptosis was less prevalent and ranged from $3.83 \pm 1.77 \%(\mathrm{p}<0.001)$ to $6.58 \pm$ $1.99 \%(\mathrm{p}<0.0001)$. Higher levels of both Schwann/satellite cell and neuronal apoptosis were observed in 2 of the animals necropsied at 12 weeks PI (EP51 and DH50) as compared to those necropsied at 6 weeks PI (Fig. 6A). A qualitative view of the extent of the apoptosis around neurons stained with antibody to NeuN observed in the DRG is shown in Fig 6B. Fig. 6C shows the TUNEL signal (green) seen in Schwann cells/satellite cells labeled with antibody to S-100 followed by secondary antibody conjugated to Alexa fluor 568 (red) that are surrounding a neuron that appears unstained as it does not take up S-100, but is also showing the TUNEL signal in the center and traces of B. burgdorferi antigen (blue) stained with antibody to whole B. burgdorferi followed by secondary antibody conjugated to Alexa fluor 633. Apoptotic DRG neurons in the vicinity of $B$. burgdorferi antigen are shown in Fig. 6D. No significant oligodendrocyte or neuronal apoptosis was detected in the tissues collected from the various regions of the brain and spinal cord. Apoptosis was not detected in astrocytes or microglia in any of the tissues.

\section{Discussion}

This study depicts an in vivo model of acute LNB in the rhesus monkey. The model evidences the key features of CSF pleocytosis, as well as the classical lesions of leptomeningitis of brain and spinal cord and radiculitis that have been reported in patients with early LNB [2,4,11-15]. Importantly, live spirochetes were detected by culture of CSF cell pellets and CNS tissues collected post-mortem. This finding provides evidence of active CNS infection in this model.

Elevated CSF levels of both cytokines and chemokines have been reported in Lyme meningitis patients. The model not only reproduced these features but also provided, in addition, an insight into whether key inflammatory mediators did originate within the CNS or in the periphery, and an indication of the cellular sources of these mediators. That glia, and thus innate immune processes, are at least in part the source of relevant cytokines and chemokines was further suggested by the very early appearance of pleocytosis, likely caused by the enhanced concentration of these mediators in CSF within the first week PI. Acquired immunity, measured as serum antibody to VlsE, was only evident by week 3 PI, and later than week 3 in most animals. Perhaps the most significant finding was that of neuronal and Schwann/satellite cell apoptosis in DRG. As we discuss below, this phenomenon 
A

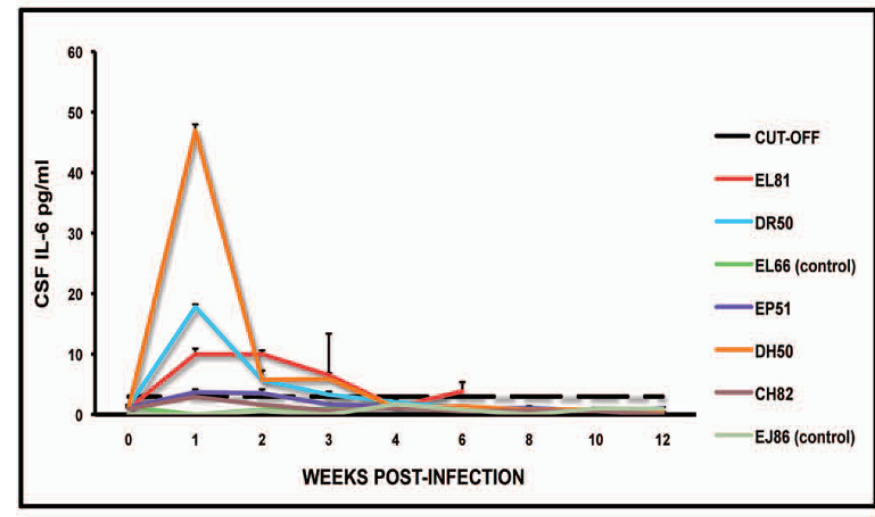

C

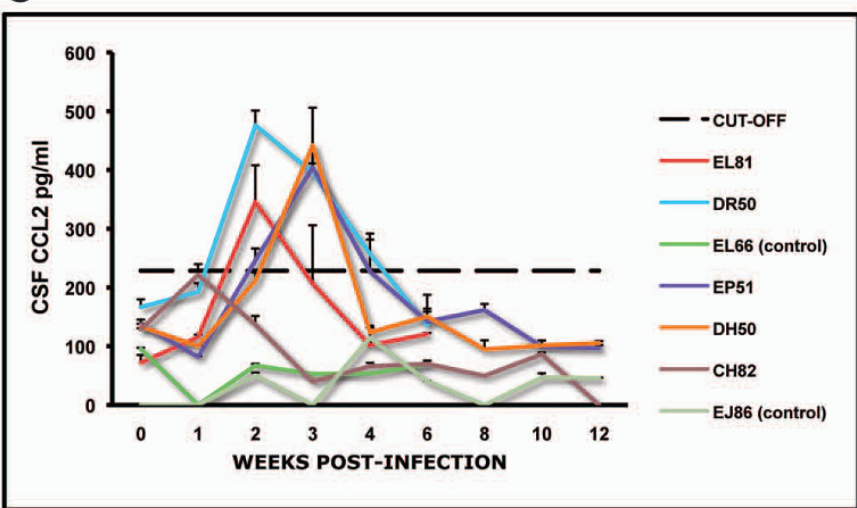

B

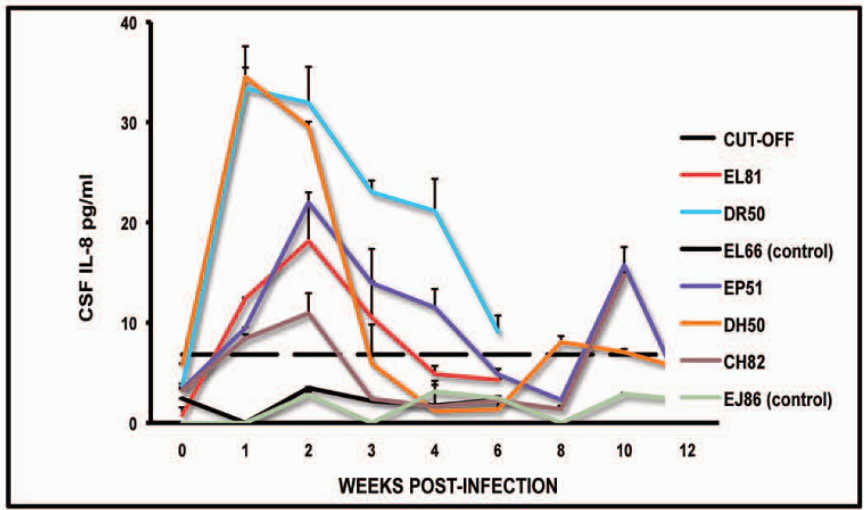

D

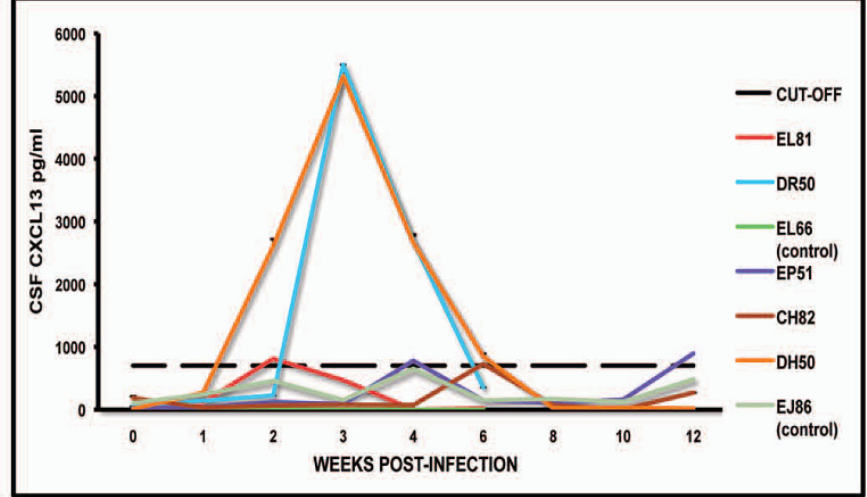

Figure 2

Early appearance of cytokines and chemokines in the CSF. Levels of IL-6 (A), IL-8 (B), CCL2 (C) and CXCLI 3 (D) in the CSF of all of the animals in the study as a function of time PI. The dotted line represents the cut-off value obtained as described in Materials and Methods. Data represent the mean \pm SD of duplicate determinations except for CXCLI3, where availability of CSF only permitted duplicate determinations for all data points of animal DH50, and some data points of animals DR50 and $\mathrm{CH} 82$.

provides a probable etiology for Lyme neuroborreliosis of the PNS.

The evidence of pleocytosis by weeks 1-2 PI in all of the inoculated animals coincided with elevated levels of immune mediators (Table 1, Fig 2). This correlation indicates, but does not prove, that these immune mediators had a role in mobilizing the immune cells from the periphery into the CNS. The low levels of pleocytosis and immune mediators in animal $\mathrm{CH} 82$, as well as the lack of anti-C6 antibody response, could be due to an early clearance of active infection in this animal.

The ability to culture spirochetes from CSF cell pellets and CNS tissue and the occurrence of pleocytosis concomitant with an increase of immune mediators in the CSF implies that these phenomena occurred as a response to the presence of live spirochetes and spirochetal antigens in the CNS. The influx of immune cells from the periphery into the CNS is reflected in the cellular composition of the inflammatory lesions that were identified in the brain, spinal cord, dorsal root nerves and DRG of infected animals. The presence of B. burgdorferi antigen in CNS tissues and DRG located in the vicinity of inflammatory lesions indicates that the Lyme spirochete could have contributed to the induction of the acute inflammatory response both in the CNS as well as the PNS (DRG).

As chemokines are known to regulate inflammatory processes in the CNS in various bacterial and viral meningitides [26], acute Lyme meningitis could also be initiated via signaling mechanisms mediated by cytokines and chemokines, produced by glial cells in response to the Lyme spirochete. The presence of T cells and monocytes in lesions and in the CSF of spirochete-inoculated animals in this study, as well as those observed in the CSF of human patients with LNB, could be a consequence of the chemotactic action of the chemokine CCL2/MCP-1 $[13,37,38]$; 

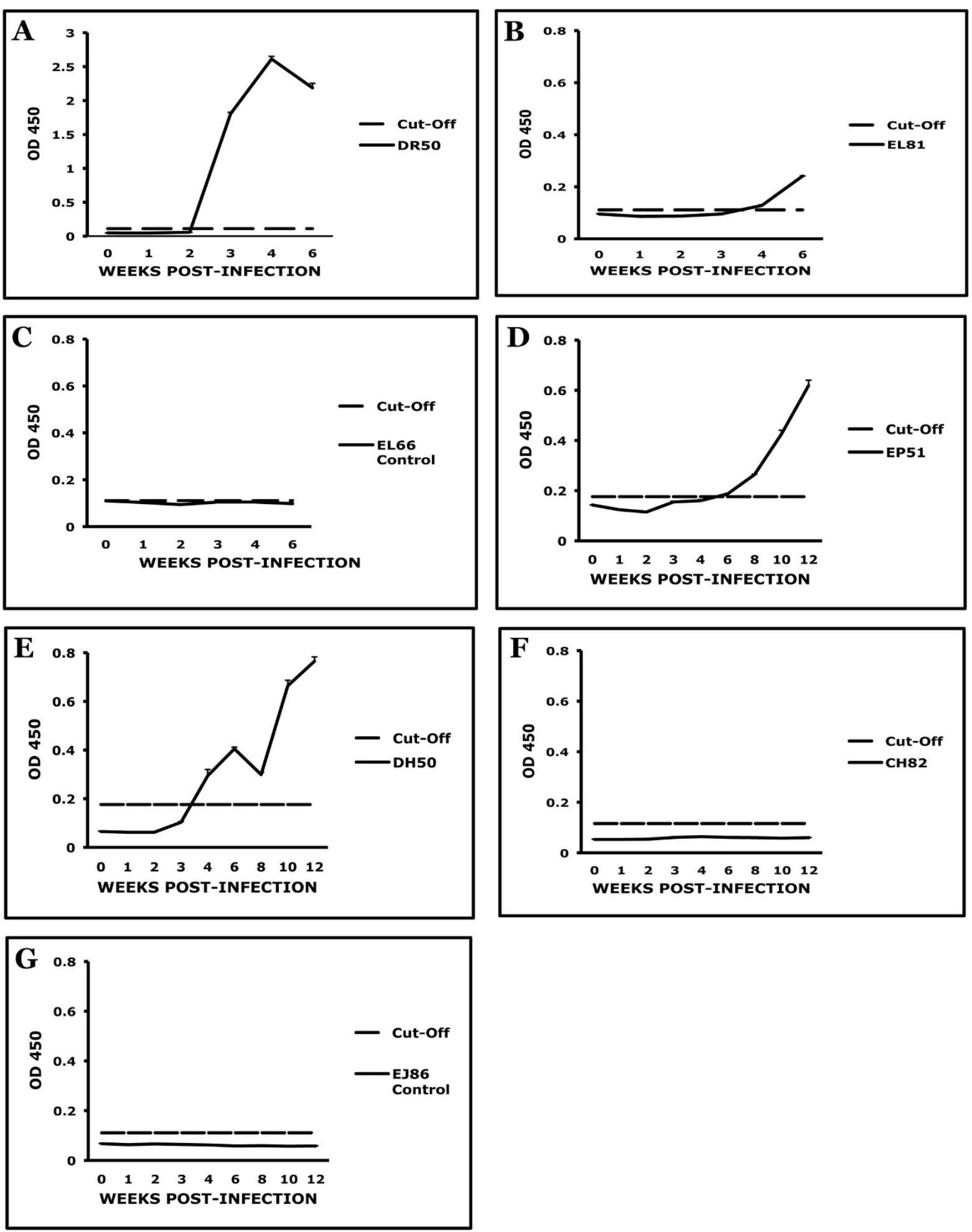

Figure 3

Emergence of the acquired immune response only after week 3 PI. C6 (VlsE) serum-antibody levels as a function of time PI, as measured by C6 ELISA in B. burgdorferi-infected animals. A. DR50, B. EL8I, C. EL66, D. EP5I, E. DH50, F. CH82, and $G$ EJ86. The dotted line represents the cut-off value obtained as described in Materials and Methods. Data represents mean \pm SD of triplicate determinations. 


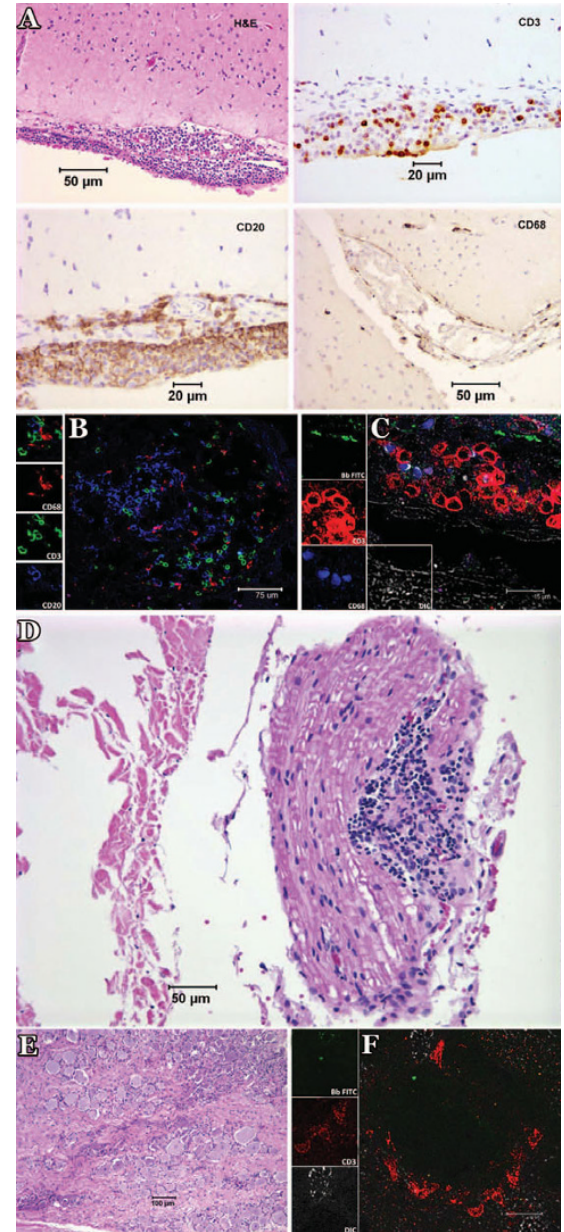

Figure 4

Histopathological evaluation and immunofluorescence staining of lesions in the brain, dorsal root nerves and DRG. A) Composite light microscope image of leptomeningitis in the brain of a $B$. burgdorferi-inoculated animal (DR50) showing lymphocytic, plasmacytic and monocytic infiltration by hematoxylin and eosin staining, as well as immunohistochemical staining showing CD3-labeled T cells, CD-20-labeled B cells, and CD68-labeled macrophages. B) Confocal micrograph showing immunofluorescence staining of CD3-labeled T cells (green), CD20-labeled B cells (blue) as well as CD68-labeling macrophages (red) in a representative inflammatory lesion from the meninges of animal DR50. C) FITC-labeled B. burgdorferi antigen (green) in the vicinity of CD3-staining T cells (red) and CD68-staining macrophages in lesions found in the frontal cortex of animal DR50. D)

Radiculitis in the dorsal root of a cervical spinal nerve proximal to the ganglion of animal DH50. There is abundant lymphocytic, and monocytic infiltration as well as plasma cells. A few adjacent nerve fibers have swollen sheaths. E) Chronictype inflammation of DRG from animal DH50 showing infiltrates of lymphocytes, plasma cells, and monocytes. F) $B$. burgdorferi antigen stained with antibody to $B$. burgdorferi labeled with FITC, in the vicinity of the CD3-staining T cells (red) in lesions found in DRG of animal DR50. this chemokine is also involved in enhancing production of inflammatory/immune cells from the bone marrow, an important feature that can assist in recruitment of these cells to the CNS. CCL2 was evident in the CNS as early as week 2 PI, and was shown to be produced by microglia. Moreover, its concentration in the CSF was up to 11 times higher than it was in the serum, in paired specimens of both fluids (Table 3); this is evidence to suggest that CCL2 was initially produced in the CSF. Considering that this chemokine has other important functions in the CNS, such as altering blood-brain barrier permeability [39], and affecting the survival of neuronal cells in other inflammatory neurodegenerative diseases such as multiple sclerosis and Alzheimer's disease [21,23,28,40-44], CCL2 could possibly be a contributor to the neurodegeneration $[21,44]$ and vasculitis $[3,44]$ observed in LNB.

The abundance of B cells in the lesions of spirochete-inoculated animals could be a consequence of the chemotactic activity of the B lymphocyte chemoattractant CXCL13. This chemokine was elevated in CSF by week 2 PI, and the fact that its concentration in CSF was in most cases higher than in paired serum specimens indicates, as with CCL2, that CXCL13 was primarily produced in the CNS. Our finding that microglia are among the cells that serve as a source of CXCL13 in the CNS corroborates our previous results that document the production of this chemokine by microglia in rhesus monkey brain explants that were exposed to B. burgdorferi [22]. It also echoes the observations of others who suggested a role for CXCL13 in LNB $[24,25]$, and entails a possible driving force for the intrathecal B-cell infiltration and antibody production commonly observed in patients with spirochetal diseases.

The neutrophil attractant IL-8, which was detected in the CSF as early as week one PI, is likely a cause of the early accumulation of neutrophils in the CSF. Interestingly, even at this early time point, the concentration of IL- 8 in serum was up to 100 times higher than that in the CSF (Table 3). No IL-8 was found in glial cells, in tissues collected at necropsy, even though this cytokine is produced in vitro both by astrocytes and microglia co-cultured with B. burgdorferi [23].

IL-6, which was already elevated in CSF by week one PI, could be contributed by glial cells, based on our observation of the localization of IL- 6 to astrocytes, as well as to neurons. IL- 6 has been documented to play a role in mediating inflammation in various inflammatory diseases of the nervous system [45-48] and in the pathogenesis of LNB $[49,50]$. Our observations affirm our previous report documenting astrocyte-derived IL-6 in response to live B. burgdorferi [22]. We have also previously shown that live B. burgdorferi as well as purified lipoproteins from 

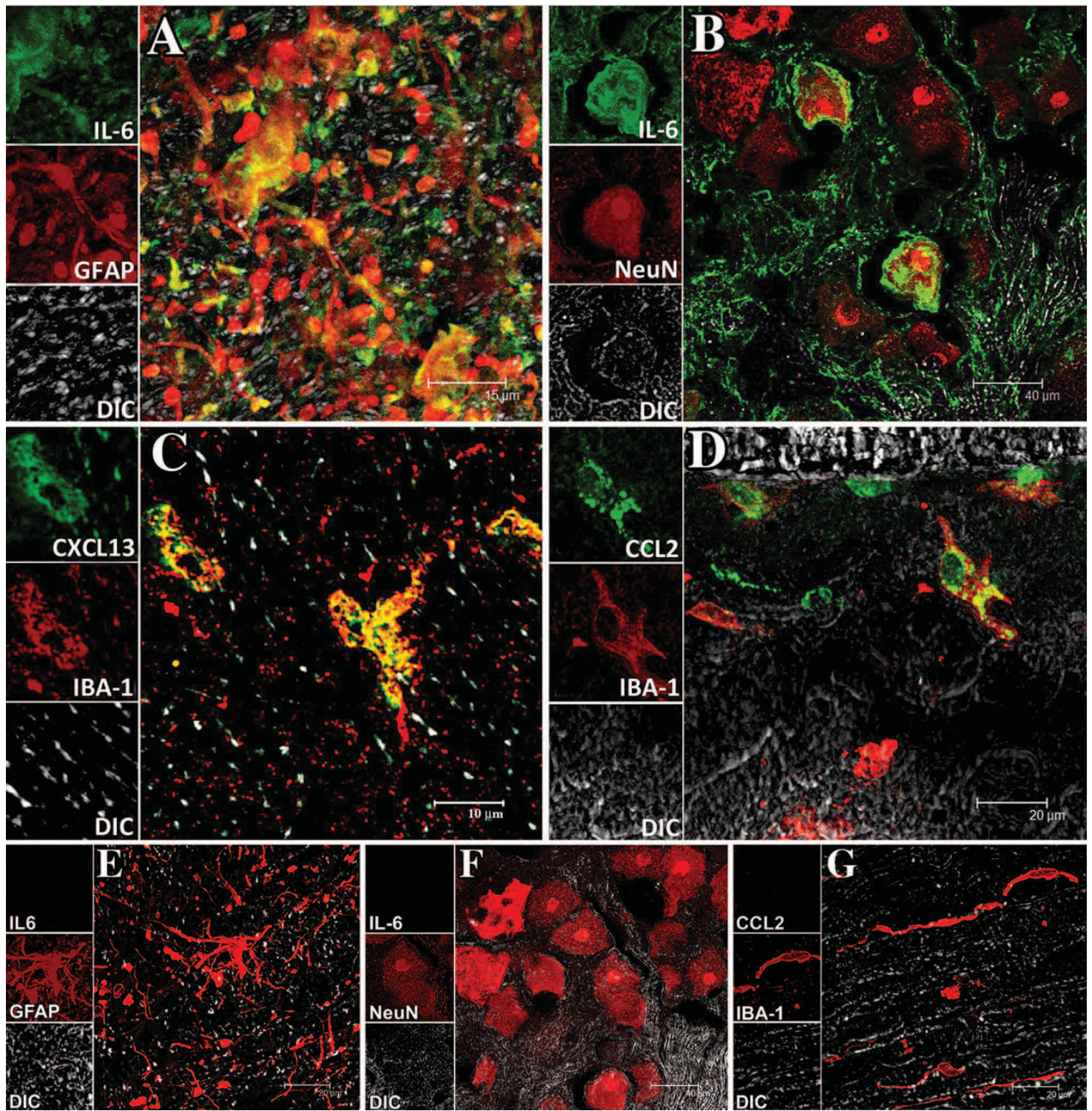

\section{Figure 5}

Visualization of immune mediators and their producer cells in the CNS of B. burgdorferi-infected animals. A) Indication of the cytokine IL-6 (green) due to staining with anti-IL-6 antibody followed by secondary antibody conjugated with Alexa fluor 488, in astrocytes (red), due to staining with anti-GFAP-cy3 in the spinal cord of animal DH50. The yellow signal is due to co-localization of the astrocytic marker GFAP (red) and IL-6 (green) within the astrocytes. B) The cellular localization of IL-6 (green) in neurons appearing red due to staining with anti-NeuN antibody, followed by secondary antibody conjugated with Alexa fluor 568. As NeuN is a nuclear antigen it is seen to stain the neuronal nucleus, while IL-6 is evident in the cytoplasm and extracellularly. C) The presence of CXCLI 3 (green) due to staining with anti-CXCLI 3 antibody followed by secondary antibody conjugated with Alexa fluor 488, in microglia (red) due to staining with anti-IBA-I followed by secondary antibody conjugated to Alexa fluor 568 in the spinal cord of animal DH50. Intracytoplasmic staining of CXCLI 3 in microglia appears yellow. D) Evidence of CCL2 (green) due to staining with anti-CCL2 antibody followed by secondary antibody conjugated with Alexa fluor 488, in microglia (red) in the spinal cord of DH50. E). A representative image of the absence of IL- 6 (which should have appeared green due to labeling with anti-IL-6 antibody followed by secondary antibody conjugated to Alexa fluor 488) in astrocytes labeled with anti-GFAP-cy3 (red) in the spinal cord of a control animal. F). Absence of IL-6 in neurons appearing red due to staining with anti-NeuN antibody, followed by secondary antibody conjugated with Alexa fluor 568 in the DRG of a control animal. G). Absence of CCL2 in microglia (red) due to staining with anti-IBA-I followed by secondary antibody conjugated to Alexa fluor 568 in the spinal cord of control animals. The unstained tissue in all images appears gray due to differential interference contrast (DIC) imaging. 


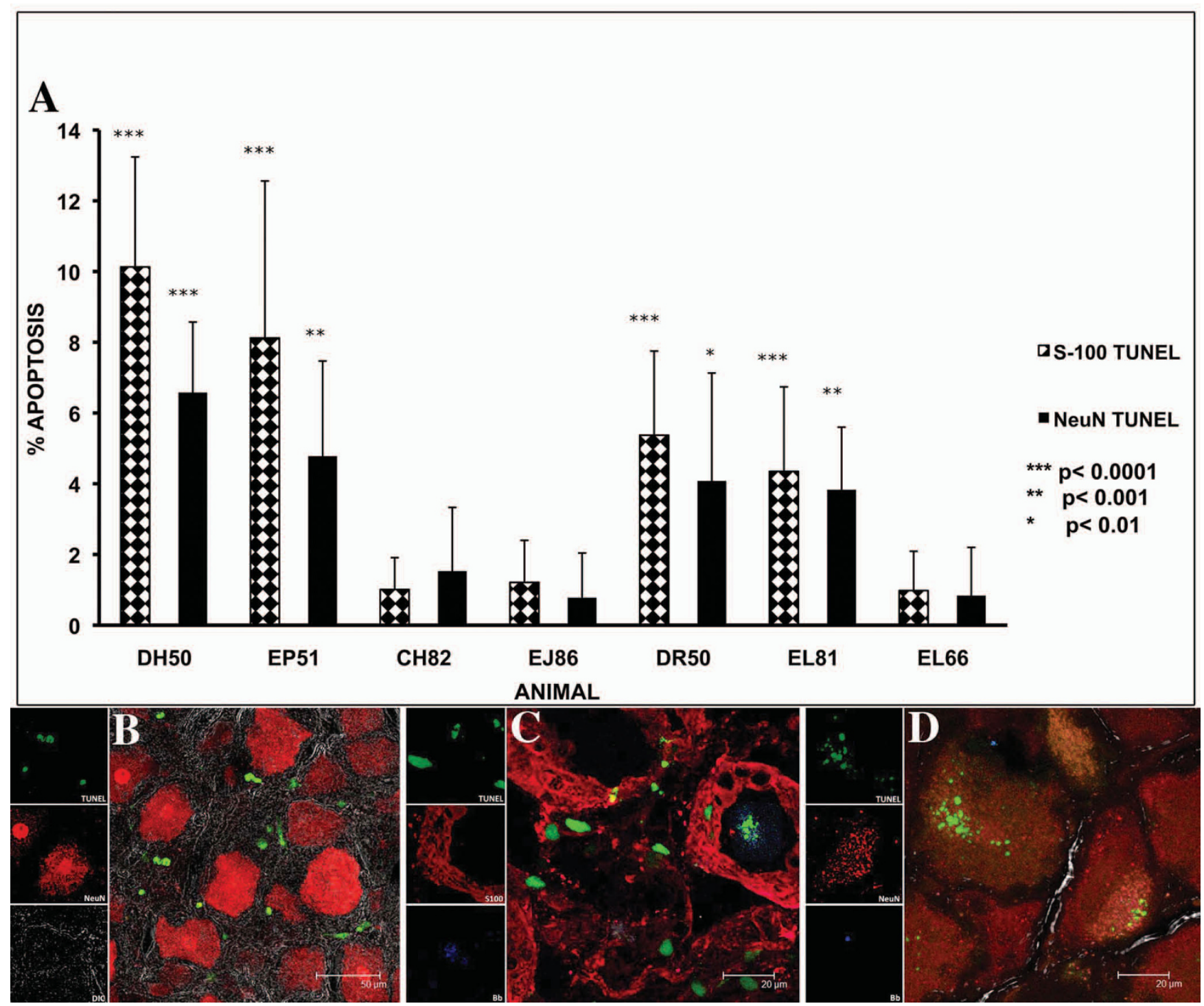

Figure 6

Schwann cell and/or Satellite cell and neuronal apoptosis in DRG. A) Percentage of Schwann/satellite cells and neurons dying by apoptosis as revealed by the in situ TUNEL assay performed on tissues from the DRG of all of the animals in the study. Data represent the mean values \pm SD of the counts from ten fields. The $P$ values represent the statistical significance with respect to the control animal (EL66 wk 6 and EJ86 wk 12) for each group. B) A qualitative view of the extent of the apoptosis (green) around neurons stained with antibody to NeuN followed by secondary antibody conjugated to Alexa fluor 568 (red) observed in the DRG of DH50 following the in situ TUNEL assay and immunofluorescence staining and confocal microscopy. C) Apoptosis of DRG Schwann/satellite cells. DRG sections from animal DH50 were labeled with antibody to S-I00, followed by secondary antibody conjugated to Alexa fluor 568 (red). Cells undergoing apoptosis, stained using the TUNEL assay, are shown in green (FITC). Apoptotic Schwann/satellite cells surround a neuron that appears unstained as it does not take up the S- 100 antibody, but is also showing the TUNEL signal in the center. D) Neurons stained with anti-NeuN antibody (red), and undergoing apoptosis (green) are shown in the vicinity of residual $B$. burgdorferi antigen (blue). The confocal micrograph is from a DRG section of animal DH50, following application of the in situ TUNEL assay and immunofluorescence staining. $B$. burgdorferi antigen is seen as blue due to labeling with anti-whole-cell B. burgdorferi antigen followed by secondary antibody conjugated to Alexa 633 . 
this spirochete are able to induce the production of IL- 6 in primary cultures of rhesus glial cells $[23,51]$.

The role of microglia in initiating or promoting inflammatory processes in the CNS by facilitating the recruitment of peripheral immune cells has been well documented [52-54]. Here, we show that microglia can contribute the chemokines CCL2 and CXCL13 in the CNS and that the innate immune response mounted against the Lyme spirochete in the CNS, as evidenced by the appearance of immune mediators in the CSF, occurs before the onset of the acquired immune response. The latter was measured by the appearance of anti-C6 (VlsE) serum antibody. The induction of a syndrome indistinguishable from acute LNB prior to the onset of specific acquired immunity indicates that this syndrome can be induced by innate immune mechanisms, thus providing an insight into the pathogenesis of the acute form of the disease.

An important finding of this study is the significant Schwann/satellite cell and neuronal apoptosis in the DRG of B. burgdorferi-infected animals. This finding corroborates previous observations made in an ex vivo model of the interaction of live B. burgdorferi with brain explants from the frontal cortex of rhesus brain [22]. Our failure to find significant apoptosis in the brain and spinal cord in the in vivo model may be due to limited interaction of $B$. burgdorferi with parenchymal tissue, compounded with clearance of apoptotic cells by phagocytes such as macrophages and microglia [55]. In contrast, the detection of apoptotic cells in the DRG could be brought about by a delay in the recruitment of phagocytic cells to this area or by the presence of a larger concentration of neurons and Schwann/satellite cells per unit volume in the DRG as compared to neurons and oligodendrocytes in the parenchyma.

Mechanisms of neuronal damage as a consequence of bacterial meningitis have been studied extensively $[56,57]$. Neural injury has been documented in experimental neonatal meningitis due to group B streptococci [58]. The neurological sequelae of meningitis caused by Streptococcus pneumoniae also include neuronal dysfunction due to neuronal apoptosis [59]. Similar mechanisms of neuronal damage and neuronal dysfunction could be contributing to the cognitive and memory impairment seen in patients with LNB.

Neuroinflammation during bacterial meningitis is known to affect both neuronal synaptic plasticity as well as neuronal survival. Death of Schwann/satellite cells could also result in impaired neuronal function $[60,61]$. As we have shown that Lyme meningitis sets the stage for neuroinflammation and Schwann/satellite cell and neuronal damage, immune-mediated glial and neuronal damage could be among the underlying mechanisms of the cognitive and memory loss seen in LNB patients. The axonal damage observed in the PNS in LNB patients as well as in the rhesus monkey model of Lyme disease $[62,63]$ could be a result of immune mediated death of DRG neurons, resulting in impaired nerve function.

Another potentially relevant finding of this study is the presence of IL-6 in neurons of DRG in infected animals. The induction of IL- 6 in neurons of adult rat DRG that are adjacent to injured peripheral nerves has been shown to be a specific response to nerve injury $[64,65]$. IL-6 is suggested to play a critical role in affecting the activity of neurons in the DRG, increasing the receptiveness of neurons at nerve endings, axons as well as nerve cell bodies, resulting in lower back pain and sciatica [66]. IL-6-mediated signaling in glial cells in the spinal cord after spinal nerve injury is also known to play a role in the transduction of pain [67]. Thus the cytokine IL-6 produced in neuronal cells in the DRG as well as in glial and neuronal cells in the spinal cord that we observed in this model could be a possible factor contributing to the transduction of the lumbar pain that is often observed in patients with LNB.

\section{Conclusion}

In conclusion, the findings of this study emphasize that glial cells are among the sources of a distinct set of immune mediators particularly the cytokines IL-6, and the chemokines CCL2 and CXCL13, in response to the Lyme spirochete in the CNS. Importantly, the observation of Schwann cell and/or satellite cell and neuronal apoptosis in the DRG as well as the inflammatory cytokine IL-6 in neurons in this region lend support to our hypothesis that the direct interaction of the spirochete with neural cells, a phenomenon that had long been predicted by experiments performed in vitro $[68,69]$, and the ensuing immune response, may result in neurological damage. Our results are consistent with the notion that innate immune responses of glial cells to the Lyme disease spirochete initiate and/or mediate the inflammation that characterizes acute Lyme meningitis, and provide evidence of concomitant apoptotic cell death in the DRG. The latter could be the early event that leads to peripheral neuropathy in LNB.

\section{Competing interests}

The authors declare that they have no competing interests.

\section{Authors' contributions}

GR prepared the B. burgdorferi inoculum, processed the CSF samples for pleocytosis, differential white blood cell analysis and culture, processed necropsy samples, conducted sandwich ELISA assays for CXCL13, performed immunofluorescence staining and confocal microscopy, 
conducted the multiplex analysis of cytokines and chemokines from CSF and serum and drafted the manuscript. JTB and PJD performed the necropsies, processed samples for immunohistochemistry and conducted the routine histopathological evaluations of slides. AG conducted the evaluation of pleocytosis and differential counts. EPR was the veterinarian who oversaw the well being of the animals; she conducted the intrathecal inoculations and harvested CSF and serum samples. LAM conducted the software acquisition and analysis of the data for the multiplex assays. PM helped with immunohistochemistry and immunofluorescence staining and confocal microscopy. DSM conducted the culture of tissues at necropsy for $B$. burgdorferi. MBJ conducted the C-6 ELISA assays. MTP is the principal investigator for this project; he produced the basic project's design and directed and coordinated its realization. He also helped in drafting and preparing the manuscript for publication.

\section{Acknowledgements}

We thank Robin Rodriguez for help with the confocal microscope images. This work was supported by the National Institutes of Health grants [NS048952, RR00 I64, to MTP].

\section{References}

I. Halperin JJ: Nervous system Lyme disease. Infect Dis Clin North Am 2008, 22:26I-274. vi.

2. Halperin JJ: Neuroborreliosis. Am J Med 1995, 98:56S-59S. discussion $56 \mathrm{~S}-59 \mathrm{~S}$

3. Rupprecht TA, Koedel U, Fingerie V, Pfister HW: The pathogenesis of Lyme neuroborreliosis: from infection to inflammation. Mol Med 2008, 14:205-212.

4. Gustaw K, Beltowska K, Studzinska MM: Neurological and psychological symptoms after severe acute neuroborreliosis. Ann Agric Environ Med 2001, 8:91-94.

5. Fishman RA: Cerebrospinal Fluid in Diseases of the Nervous System Philadelphia, USA: W. B. Saunders Company; 1992:253-343.

6. Leist TP, Frei K, Kam-Hansen S, Zinkernagel RM, Fontana A: Tumor necrosis factor $\alpha$ in cerebral fluid during bacterial, but not viral meningitis. Evaluation in murine model infections and patients. J Exp Med 1988, 167:1743-1748.

7. Täuber MG, Moser B: Cytokines and chemokines in meningeal inflammation: biology and clinical implications. Clin Infect Dis 1999, 28:1-1I.

8. Ramilo O, Sáez-Llorens $X$, Mertsola J, Jafari H, Olsen KD, Hansen EJ, Yoshinaga M, Ohkawara S, Nariuchi H, McCracken GH Jr: Tumor necrosis factor alpha/cachectin and interleukin Ibeta initiate meningeal inflammation. J Exp Med 1990, 172:497-507.

9. Huber AR, Kunkel SL, Todd RF, Weiss ST: Regulation of transendothelial neutrophil migration by endogenous interleukin 8. Science 1991, 254:99-102.

10. Jiang Y, Beller DI, Frendl G, Graves DT: Monocyte chemoattractant protein-I regulates adhesion molecule expression and cytokine production in human monocytes. J Immunol 1992, | 48:2423-2428.

II. Holub M, Kluckova Z, Beran O, Aster V, Lobovska A: Lymphocyte subset numbers in cerebrospinal fluid: comparison of tickborne encephalitis and neuroborreliosis. Acta Neurol Scand 2002, 106:302-308.

12. Pietruczuk A, Swierzbinska R, Pietruczuk M, Hermanowska-Szpakowicz T: Role of interleukin- | 8, interleukin- I beta and its soluble receptor (sIL-IRII) in early and late Lyme borreliosis. Pol Merkuriusz Lek 2004, I 7:446-450.

13. Grygorczuk S, Zajkowska J, Swierzbinska R, Pancewicz S, Kondrusik $M$, Hermanowska-Szpakowicz T: Concentration of interferoninducible $T$ cell chemoattractant and monocyte chemotactic protein-I with Lyme borreliosis. Annal Acade Medic Bial 2005, 50:173-178.
14. Cepok S, Zhou D, Vogel F, Rosche B, Grummel V, Sommer N, Hemmer $B$ : The immune response at onset and during recovery from Borrelia burgdorferi meningoradiculitis. Arch Neurolog 2003, 60:849-855.

15. Weller M, Stevens A, Sommer N, Wietholter H, Dichgans J: Cerebrospinal fluid interleukins, immunoglobulins, and fibronectin in neuroborreliosis. Arch Neurol 199I, 48:837-84I.

16. Wang WZ, Fredrikson S, Sun JB, Link H: Lyme neuroborreliosis: evidence for persistent up-regulation of Borrelia burgdorferi reactive cells secreting interferon-gamma. Scand J Immunol 1995, 42:694-700.

17. Ekerfelt C, Jarefors S, Tynngård N, Hedlund M, Sander B, Bergström $S$, Forsberg P, Ernerudh J: Phenotypes indicating cytolytic properties of Borrelia -specific interferon-gamma secreting cells on chronic Lyme neuroborreliosis. J Neuroimmunol 2003, 145: II5-126.

18. Kondrusik M, Sweirzbinska R, Pancewicz S, Zajkowska J, Grygorczuk $S$, Hermanowska-Szpakowicz T: Evaluation of proinflammatory cytokine (TNF-alpha, IL-I beta, IL-6, IFN-gamma) concentrations in serum and cerebrospinal fluid of patients with neuroborreliosis. Neurol Neurochir Pol 2004, 38:265-70.

19. Widhe M, Grusell M, Ekerfelt C, Vrethem M, Forsberg P, Emerudh J: Cytokines in Lyme borreliosis: lack of early tumour necrosis factor-alpha and transforming growth factor-betal responses are associated with chronic neuroborreliosis. Immunology 2002, 107:46-55.

20. Oksi J, Kalimo H, Marttila RJ, Marjamäki M, Sonninen P, Nikoskelainen J, Viljanen MK: Inflammatory brain changes in Lyme borreliosis. A report on three patients and review of literature. Brain 1996, II 9:2143-2154.

21. Benach JL, Garcia-Monco JC: Aspects of the pathogenesis of neuroborreliosis. In Lyme disease; Molecular and immunological approaches Edited by: Schutzer S. New York: Cold Spring Harbor Press; 1992.

22. Ramesh G, Borda JT, Kaushal D, Ramamoorthy R, Lackner AA, Philipp $M T$ : Interaction of the Lyme disease spirochete Borrelia burgdorferi with brain parenchyma elicits inflammatory mediators from glial cells as well as glial and neuronal apoptosis. Am J Pathol 2008, 173:1415-1427.

23. Bernardino ALF, Myers TA, Alvarez X, Hasegawa A, Philipp MT: Tolllike receptors: Insights into their possible role in the pathogenesis of Lyme neuroborreliosis. Infect Immun 2008, 76:4385-4395.

24. Narayan K, Dail D, Li L, Cadavid D, Amrute S, Fitzgerald-Bocarsly P, Pachner AR: The nervous system as ectopic germinal center: CXCLI 3 and IgG in Lyme neuroborreliosis. Ann Neurol 2005, 57:813-823.

25. Rupprecht TA, Pfister HW, Angel B, Kastenbauer S, Wilske B, Koedel $U$ : The chemokine CXCLI3 (BLC): a putative diagnostic marker for neuroborreliosis. Neurology 2005, 65:448-450.

26. Lahrtz F, Piali L, Spanausk S, Seebach J, Fontana A: Chemokines and chemotaxis of leukocytes in infectious meningitis. J Neuroimmunol 1998, 85:33-43.

27. Mahad DJ, Ransohoff RM: The role of MCP-I/CCL2 and CCR2 in multiple sclerosis and experimental autoimmune encephalitis (EAE). Semin Immunol 2003, 15:23-32.

28. Huang D, Han Y, Rani MR, Glabinski A, Trebst C, Sørensen T, Tani M, Wang J, Chien P, O'Bryan S, Bielecki B, Zhou ZL, Majumder S, Ransohoff RM: Chemokines and chemokine receptors in inflammation of the nervous system: manifold roles and exquisite regulation. Immunol Rev 2000, 177:52-67.

29. Liang FT, Philipp MT: Analysis of antibody response to invariable regions of VIsE the variable surface antigen of Borrelia burgdorferi. Infect Immun 1999, 67:6702-6706.

30. Marra CM, Castro CD, Kuller L, Dukes AC, Centurion-Lara A, Morton WR, Lukehart SA: Mechanisms of clearance of Treponema pallidum from the CSF in a nonhuman primate model. Neurology 1998, 5 I:957-961.

31. Philipp MT, Aydintug MK, Bohm RP Jr, Cogswell FB, Dennis VA, Lanners HN, Lowrie RC Jr, Roberts ED, Conway MD, Karaçorlu M, Peyman GA, Gubler DJ, Johnson BJ, Piesman J, Gu Y: Early and earlydisseminated phases of Lyme disease in the rhesus monkey: A model of infection in humans. Infect Immun 1993, 61:3047-3059.

32. Pachner AR, Delaney E, O'Neil T, Major E: Inoculation of nonhuman primates with the N40 strain of Borrelia burgdorferi 
leads to a model of Lyme neuroborreliosis faithful to the human disease. Neurology 1995, 45:165-72.

33. Cadavid D, O'Neil T, Schaefer H, Pachner AR: Localization of Borrelia burgdorferi in the nervous system and other organs in a nonhuman Primate model of Lyme disease. Lab Invest 2000, 80:1043-1054

34. Bai Y, Narayan K, Dail D, Sondey M, Hodzic E, Barthold SW, Pachner $A R$, Cadavid $D$ : Spinal cord involvement in the nonhuman primate model of Lyme disease. Lab Invest 2004, 84:160-I72.

35. Ramesh G, Alvarez X, Borda JT, Aye PP, Lackner AA, Sestak K: Visualizing cytokine-secreting cells in situ in the rhesus macaque model of chronic gut inflammation. Clin Diagn Lab Immunol 2005, I 2(I): 192-197.

36. Albuerne M, Mammola CL, Naves FJ, Levanti B, Germanà G, Vega JA: Immunohistochemical localization of $\mathrm{S} I 00$ proteins in dorsa root, sympathetic and enteric ganglia of several mammalian species, including man. J Peripher Nerv Syst 1998, 3:243-253.

37. Randolf G], Furie MB: A soluble gradient of endogenous monocyte chemoattractant protein-I promotes the transendothelial migration of monocytes in vitro. J Immunol 1995, 155:3610-18.

38. Carr MW, Roth SJ, Luther E, Rose SS, Springer TA: Monocyte chemoattractant protein-I acts as a T-lymphocyte chemoattractant. Proc Natl Acad Sci USA 1994, 91:3652-3656.

39. Dimitrijevic OB, Stamatovic SM, Keep RF, Andjelkovic AV: Effects of the chemokine CCL2 on blood-brain barrier permeability during ischemia-reperfusion injury. J Cereb Blood Flow Metab 2006, 26:797-810.

40. Voorn P Van der, Tekstra J, Beelen RHJ, Tensen CP, Valk P Van der, De Groot CJA: Expression of MCP-I by reactive astrocytes in demyelinating multiple sclerosis lesions. Am J Pathol 1999, I54:45-5I.

41. Babcock AA, Kuziel WA, Rivest S, Owens T: Chemokine expression by glial cells directs leukocytes to sites of axonal injury in the CNS. J Neurosci 2003, 23:7922-7930.

42. Grammas P, Ovase R: Inflammatory factors are elevated in brain microvessels in Alzheimer's disease. Neurobiol Aging 200I, 22:837-842.

43. Huang DR, Wang J, Kivisakk P, Rollins BJ, Ransohoff RM: Absence of monocyte chemoattractant protein $I$ in mice leads to decreased local macrophage recruitment and antigen-specific $\mathbf{T}$ helper cell type $\mathbf{I}$ immune response in experimental autoimmune encephalomyelitis. J Exp Med 200 I, 193:7 I3-726.

44. Klingebiel R, Bendorf G, Schmitt M, von Moers A, Lehmann R: Large cerebral vessel occlusion disease in Lyme neuroborreliosis. Neuropediatrics 2002, 33:37-40.

45. Gadient RA, Otten UH: Interleukin-6 (IL-6) a molecule with both beneficial and destructive potential. Prog Neurobiol 1977, 52:379-390.

46. Raivich G, Jones LL, Werner A, Bluthmann H, Doetschmann T, Kreutzberg GW: Molecular signals for glial activation: Pro- and antiinflammatory cytokines in the injured brain. Acta Neurochir 1999:21-30.

47. Benveniste EN: Inflammatory cytokines within the central nervous system: sources, functions, and mechanisms of action. Am J Physiol 1992, 263: Cl-C5.

48. Gareth RJ, Lee SC, Brosnan CF: Cytokines: Powerful regulators of glial cell activation. Neuroscientist 2003, 9:10-22.

49. Habicht GS, Katona LI, Benach Jl: Cytokines and the pathogenesis of neuroborreliosis: Borrelia burgdorferi induces glioma cells to secrete interleukin-6. J Infect Dis 1991, 164:568-574.

50. Pachner AR, Amemiya K, Delaney E, O'Neil T, Hughes CAN, Zhang WF: Interleukin-6 is expressed at high levels in the CNS in Lyme neuroborreliosis. Neurology 1997, 49:147-I52.

5I. Ramesh G, Alvarez AL, Roberts ED, Dennis VA, Lasater BL, Alvarez $X$, Philipp MT: Pathogenesis of Lyme neuroborreliosis: Borrelia burgdorferi lipoproteins induce both proliferation and apoptosis in rhesus monkey astrocytes. Eur J Immunol 2003, 33:2539-2550.

52. Kielian T: Microglia and chemokines in infectious diseases of the nervous system views and reviews. Front Biosci 2004, 9:732-750.

53. Ransohoff RM, Glabinski A, Tani M: Chemokines in immunemediated inflammation of the central nervous system. Cytokine and Growth Factor Rev 1996, 7:35-46.
54. Cartier L, Hartley O, Dubois-Dauphin M, Krause KH: Chemokine receptors in the central nervous system: role in brain inflammation and neurodegenerative diseases. Brain Res Rev 2005, 48: $16-42$.

55. Maderna P, Godson C: Phagocytosis of apoptotic cells and resolution of inflammation. Biochim Biophys Acta 2003, 1639:|4|-|5|.

56. Scheld WM, Koedel U, Nathan B, Pfister Hans W: Pathophysiology of bacterial meningitis: Mechanism(s) of neuronal injury. J Infec Dis 2002, 186(Suppl 225-S233):.

57. Nau R, Brück W: Neuronal injury in bacterial meningitis: mechanisms and implications for therapy. Trends Neurosci 2002, 25:38-45

58. Kim YS, Sheldon RA, Elliot BR, Liu Q, Ferriero DM, Tauber MG: Brain injury in experimental neonatal injury due to group $B$ streptococci. J Neuropathol Exp Neurol 1995, 54:53I-539.

59. Mitchell L, Smith SH, Braun JS, Herzog KH, Weber JR, Tuomanen El: Dual phases of apoptosis in pneumococcal meningitis. J Infec Dis 2004, 190:2039-2046.

60. Jessen KR: Glial cells. Int / Biochem Cell Biol 2004, 36: I86I- I867.

61. Hanani M: Satellite glial cells in sensory ganglia: from form to function. Brain Res Rev 2005, 48:457-476.

62. England JD, Bohm R Jr, Roberts ED, Philipp MT: Mononeuropathy multiplex in rhesus monkeys with chronic Lyme disease. Ann Neurol 1997, 41:375-84.

63. Roberts ED, Bohm RP Jr, Lowrie RC Jr, Habicht G, Katona L, Piesman J, Philipp MT: Pathogenesis of Lyme neuroborreliosis in the rhesus monkey: The early disseminated and chronic phases of disease in the peripheral nervous system. J Infec Dis 1998, I 78:722-732

64. Murphy PG, Grondin J, Altares M, Richardson PM: Induction of interleukin-6 in axotomized sensory neurons. J Neurosci 1995 , I5:5130-5I38.

65. Murphy PG, Borthwick LA, Johnson RS, Kuchel G, Richardson PM: Nature of retrograde signal from injured nerves that induces interleukin-6 mRNA in neurons. J Neurosci 1999, 19:379|-3800.

66. Ozaktay AC, Kallakuri S, Takebayashi T, Cavanaugh JM, Asik I, DeLeo JA, Weinstein JN: Effects of interleukin-I beta, interleukin-6 and tumor necrosis factor on sensitivity of dorsal root ganglion and peripheral receptive fields in rats. Eur Spine / 2006, I5:1529-1537.

67. Dominguez E, Rivat C, Pommier B, Mauborgne A, Pohl M: JAK/ STAT3 pathway is activated in spinal cord microglia after peripheral nerve injury and contributes to neuropathic pain development in rat. I Neurochem 2008, 107:50-60.

68. Garcia-Moncó JC, Fernandez-Villar B, Benach JL: Adherence of the Lyme disease spirochete to glial cells and cells of glial origin. J Infect Dis 1989, 160:497-506.

69. Garcia-Moncó JC, Fernandez-Villar B, Rogers RC, Szczepanski A, Wheeler CM, Benach JL: Borrelia burgdorferi and other related spirochetes bind to galactocerebroside. Neurology 1992, $4: 134 \mid-1348$

Publish with Biomed Central and every scientist can read your work free of charge

"BioMed Central will be the most significant development for disseminating the results of biomedical research in our lifetime. "

Sir Paul Nurse, Cancer Research UK

Your research papers will be:

- available free of charge to the entire biomedical community

- peer reviewed and published immediately upon acceptance

- cited in PubMed and archived on PubMed Central

- yours - you keep the copyright 